\title{
The Efficiency of a Pulsed Detonation Combustor-Axial Turbine Integration
}

\author{
Carlos Xisto ${ }^{\mathrm{a}, *}$, Olivier Petit $^{\mathrm{a}}$, Tomas Grönstedt ${ }^{\mathrm{a}}$, Andrew Rolt $^{\mathrm{b}}$, Anders Lundbladh ${ }^{\mathrm{c}}$, \\ Guillermo Paniagua ${ }^{\mathrm{d}}$ \\ ${ }^{a}$ Dep. of Mechanics and Maritime Sciences, Chalmers University of Technology, Gothenburg, Sweden \\ ${ }^{b}$ School of Aerospace, Transport and Manufacturing, Cranfield University, Bedfordshire, UK \\ ${ }^{c}$ GKN Aerospace, Trollhättan, Sweden \\ ${ }^{d}$ Zucrow Laboratories, Purdue University, West Lafayette, Indiana, USA
}

\begin{abstract}
The paper presents a detailed numerical investigation of a pulsed detonation combustor (PDC) coupled with a transonic axial turbine stage. The time-resolved numerical analysis includes detailed chemistry to replicate detonation combustion in a stoichiometric hydrogenair mixture, and it is fully coupled with the turbine stage flow simulation. The PDC-turbine performance and flow behaviour are analyzed for different power input conditions, by varying the system purge fraction. Such analysis allows for the establishment of cycle averaged performance data and also to identify key unsteady gas dynamic interactions occurring in the system. The results obtained allow for a better insight on the source and effect of different loss mechanisms occurring in the coupled PDC-turbine system. One key aspect arises from the interaction between the non-stationary PDC outflow and the constant rotor blade speed. Such interaction results in pronounced variations of rotor incidence angle, penalizing the turbine efficiency and capability of generating a quasi-steady shaft torque. Keywords: Pulsed detonation combustor, Axial turbines, CFD, combustion modeling
\end{abstract}

\section{Introduction}

Severe environmental regulations on emissions, such as those outlined by the European vision for Aviation Flightpath 2050, has kindled research on radical engine and aircraft

*Corresponding author

Email address: carlos.xisto@chalmers.se (Carlos Xisto)

Preprint submitted to Aerospace Science and Technology

August 24, 2018 
concepts. The European Ultra Low emission Technology Innovations for Mid-century Aircraft Turbine Engines (ULTIMATE) [1] addresses the prime gas turbine engine loss sources, revealed by exergetic analysis [2], and investigates possible synergies arising from the combination of radical technologies. One of the investigated gas turbine engine concepts comprises an intercooled geared turbofan including a pulse detonation combustion (PDC) system [3].

Pulsed detonation combustors burn fuel using an intermittent, periodically initiated, detonation wave combining heat addition with a pressure increase. This should theoretically result in a lower entropy increase than the conventional Joule-Brayton cycle. Pressure rise combustion systems are believed to provide a theoretical improvement of 8 to $15 \%[3,4,5]$ in the thermal efficiency of the power plant.

Among many other very important engineering challenges, the theoretical potential of integrating pulsed detonation combustion in a gas turbine is dependent on efficient integration with a upstream compressor [6] and a downstream expansion system [7, 8, 9, 10, 11, 12]. The unsteady nature of pulsed detonation results in strong variations in mass flow, thermodynamic quantities, turbine rotor inlet angles [13], and can even lead to periods of reversed flow [14]. The turbine is therefore subjected to rapid periodic changes in operating conditions and cannot be represented by a single point in a performance map [15]. This flow behavior has a direct negative impact on the high pressure turbine efficiency, and can negate the theoretical thermal efficiency improvements of detonation combustion. Moreover, irrespective of the turbomachinery concept being investigated it is important to understand how the non-stationary PDC shock-waves $[16,17]$, influence turbomachinery flows, in particular during the early stages of detonation blowdown. The analysis of these flows are often complicated by adjacent tube interaction $[18,19]$ and tube firing sequence. A comprehensive investigation of the aforementioned unsteady processes of PDC-turbine flow is therefore crucial prior to the optimization of the PDC-axial turbine system.

Several authors characterized experimentally the effect of pulsed detonation combustors on axial and radial turbines. The experimental studies performed by Rasheed et al. [18] and Glaser et al. [20] revealed that, when the PDC flow is mixed with a steady bypass flow, the axial turbine efficiency is not strongly penalized by the fluctuations arising from the deto- 
nation chamber. Without any bypass flow, St. George [21] indicates that, for low pressure ratios, an inefficient turbine driven by PDC flow can outperform conventional engines. However, for the PDC-turbine system, the turbine efficiency was severely abated when compared with the efficiency measured under high gradient, high amplitude, non-combustion pulsating flows [13]. The aforementioned studies allowed the overall characteristics to be identified but, due to the lack of miniaturized precise measurements in such a harsh environment, they did not detail the aerothermal flow phenomena occurring across the PDC-turbine system.

Different numerical studies in PDC-axial turbine systems were also undertaken by several authors and used to support some of the aforementioned experimental investigations. Dean et al. [16] confirmed the occurrence of strong reflection waves at the turbine inlet, the decay of the detonation shock wave across the vanes, and revealed a complex non-stationary shock-wave pattern in the stator outlet. Van Zante et al. [22] studied the three-dimensional flow field in a turbine stage exposed to the outlet conditions from a PDC, set as inlet boundary condition. The results obtained by Van Zante et al. confirmed the decay in pressure fluctuations along the axial direction of the turbine, and revealed reverse flow during the early stages of blowdown. The two-dimensional numerical analysis of an axial turbine performed by Suresh et al. [23], using as inlet boundary condition the PDC outlet, indicated that efficiencies of around $70-80 \%$ are within reach.

In this paper, a PDC coupled with an axial turbine is modelled using CFD, including detailed chemistry to replicate the detonation process in a stoichiometric hydrogen-air mixture. The selected turbine geometry is the Graz transonic turbine stage at mid-span $[24,25,26]$. The time-resolved investigation is two-dimensional, using a second-order time discretization scheme. First the paper characterizes the conditions across a single PDC tube, to select a robust and cost-effective numerical method for computing detonation flow. Afterwards the unsteady flow processes in the coupled PDC-axial turbine system are presented and the prime loss mechanisms identified and discussed. 


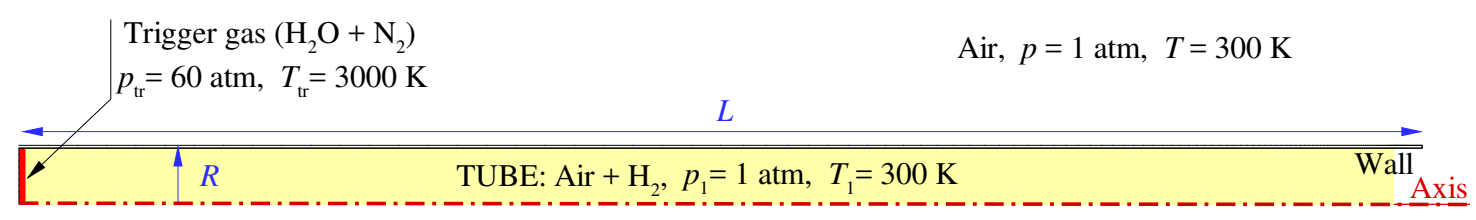

Figure 1: Partial view of the numerical domain used for the PDC-tube simulations, and initial conditions prior to detonation, $R=0.02 \mathrm{~m}, L=0.5 \mathrm{~m}$.

\section{Numerical Model}

In the present paper two different test cases are addressed. The first test case, here designated as PDC-tube, comprises a single detonation tube filled with a stoichiometric fuel-air mixture, discharging to a tank of large dimensions, as illustrated in Fig. 1. This test case is used to select and validate an adequate finite-rate reaction mechanism able to predict detonation in $\mathrm{H}_{2}$-air mixtures. Two different chemical mechanisms are analyzed: a global, single-step, reduced mechanism [27]; and a detailed mechanism comprising 19 elementary reversible reactions and 9 species [28]. The PDC-tube is only required to run during the detonation phase of a single operating cycle, the following assumptions are made:

- The fuel is assumed to be homogeneously mixed with air;

- Direct initiation is employed, meaning that a self-sustained detonation wave is formed at the closed end of the tube using a high pressure and high temperature trigger gas;

- The fuel-air mixture in the tube and the air in the tank are assumed to behave as calorically semi-perfect gases.

The second test case comprises a coupled PDC-turbine system and investigates the effect of a complete PDC cycle in an axial turbine performance. The developed model, here illustrated in Fig. 2, includes a pair of detonation tubes aligned with the rotor midspan section of the Graz transonic turbine stage $[24,25,26]$. The assumptions made in the PDC-tube test case also apply to the PDC-turbine model, further assumptions include:

- The valve opens and closes instantaneously; 

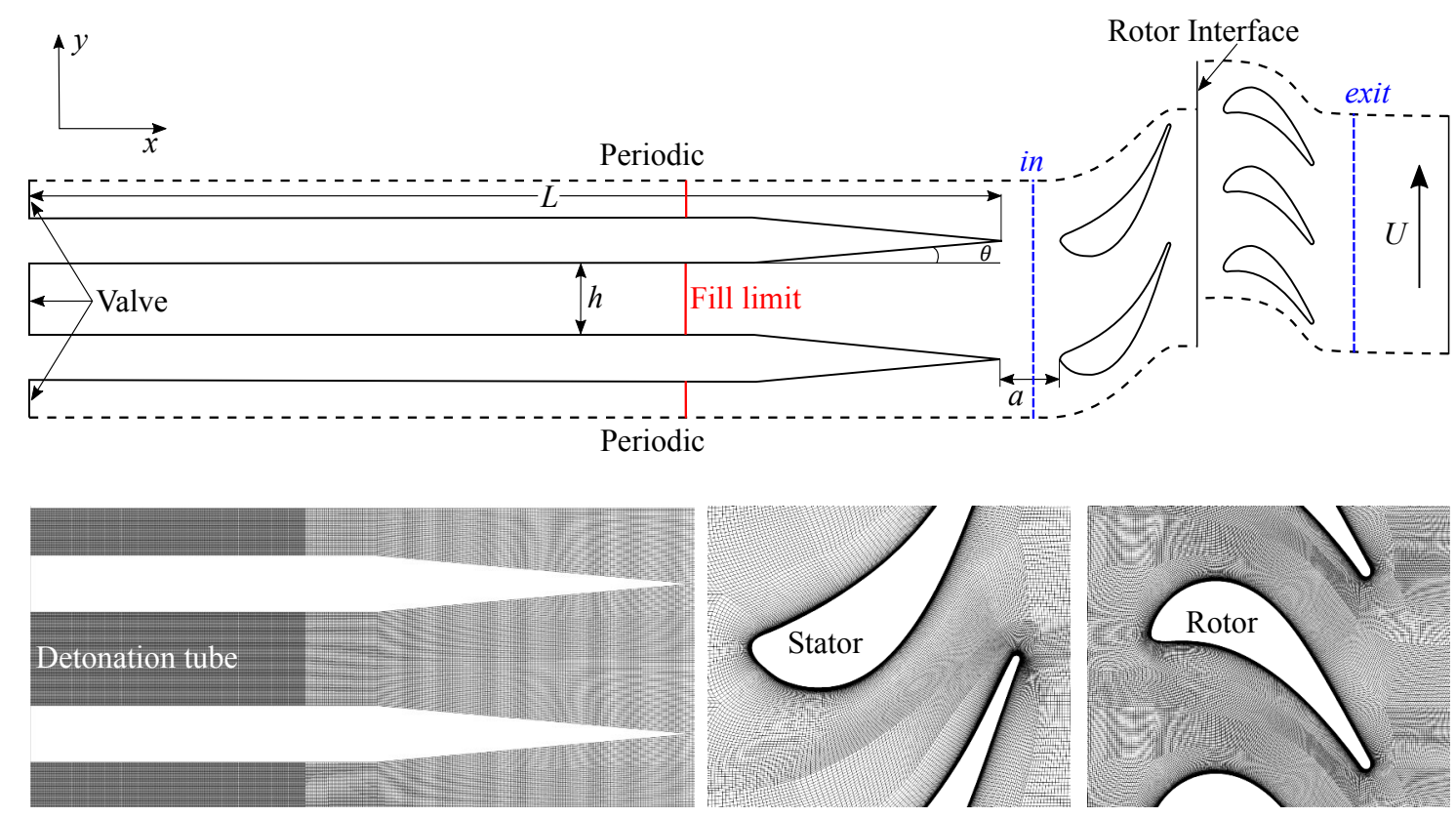

Figure 2: Model used for simulating the PDC-turbine environment, $L=0.5 \mathrm{~m} ; a=0.03 \mathrm{~m} ; h=0.038 \mathrm{~m}$; $\theta=5 \mathrm{deg}$. The instantaneous mass-weighted averaged properties are obtained at in, exit and rotor interface planes. The fill limit marks the extent of the tube to be filled with the fuel-air mixture. The image also shows the detailed views of some sections of the $2 \mathrm{D}$ numerical grid.

- The detonation tube is purged with pressurized air, and refilled with fresh reactants when the tube internal pressure is below the inlet total pressure;

- The fuel mixture and purge air are injected at subsonic speeds;

- Heat transfer is neglected (adiabatic walls), but viscous effects are taken into account. The $\mathrm{k}-\omega \mathrm{SST}$ was found suitable for predicting separated flow in this particular turbine design [29].

The above assumptions must comply with the limits and properties of detonation, which are dependent on the initial conditions, flow properties and tube geometry. A detailed explanation on how these properties are affected by the initial conditions can be found in $[30]$. 


\subsection{Detonation Initiation}

The onset of detonation is affected by the initial properties of the flow, size of the detonation tube and initiation energy. An approximate limiting value for the tube diameter is given by a direct relation to the detonation cell size. Previous works in the field revealed that the minimum diameter for reaching detonation, in stoichiometric hydrogen-air mixtures at 1 bar and $298 \mathrm{~K}$, is of the order of $6 \mathrm{~mm}[31,32]$.

In both test cases, detonation is directly initiated at the closed end of the tube(s) using a high-pressure $\left(p_{\mathrm{tr}}=60 p_{1}\right)$, high-temperature $\left(T_{\mathrm{tr}}=3000 \mathrm{~K}\right)$ trigger gas, consisting of nitrogen and water vapor, see Fig. 1 . The trigger region length is very small $\left(L_{\mathrm{tr}}=0.005 \mathrm{~L} \mathrm{~m}\right)$ compared with the total tube length and, therefore, the contribution of the trigger gas to the pressure rise in the PDC cycle is negligible [33].

The modeling of the detonation initiation as direct, enables the creation of a self-sustained detonation wave at the valve plane. This modeling has been subject to some controversy since direct initiation may require the deposition of substantial amounts of energy in each tube and detonation cycle (it can be on the order of $4.3 \mathrm{~kJ}$ for stoichiometric hydrogen - air mixtures at 1 bar and $298 \mathrm{~K}[34,32]$. Another way of achieving detonation is to use a small amount of energy to start deflagration and use a longer tube to allow a transition to detonation. However, the DDT (Deflagration to Detonation Transition) length can be prohibitively high, and may require the implementation of DDT triggering obstacles that would result in additional pressure losses. Still, the necessary length of the tube to achieve DDT increases the combustor size, and the time required to achieve detonation limits the cycle frequency. Moreover, in a real gas turbine application increased temperatures are to be produced by the compression system. Therefore, shorter tubes would also alleviate the problems associated with auto-ignition delay time. Analyzing the onset of detonation and prediction of DDT is out of the scope of the present paper, however one should take the aforementioned limitations into consideration when defining the problem boundary conditions and operation, to avoid unrealistic interpretation of the results. 


\subsection{Computational methodology}

The numerical models that will be used to simulate the single PDC-tube and PDC-axial turbine test cases are created in Ansys Fluent 17 [35]. The numerical method is based on the finite volume implementation of the two-dimensional Unsteady Reynolds-Averaged Navier-Stokes (URANS) equations. The system of equations also includes a convectiondiffusion equation for each specie involved. The finite-rate reactions are calculated with Arrhenius kinetic expressions and, due to the supersonic nature of the flame, a laminar finite-rate model is selected. For time discretization a dual-time formulation is employed, which includes the second-order backward implicit Euler method for advancing in physical time, and a pseudo-time marching 3-stages Runge-Kutta method for the inner iterations. The Courant-Friedrichs-Lewy (CFL) condition is used to select the pseudo-time step within the inner iterations, while a constant value is assumed for the physical time-step. The Roe flux-difference splitting scheme is selected to evaluate the convective fluxes and for variable interpolation the second order upwind scheme with a Total Variation Diminishing (TVD) Minmod based slope limiter is used. The fluid properties are obtained for the mixture using the mixing-law.

\subsection{Averaging Procedure}

Due to the cyclic operation of the pulsed detonation combustor, the calculation of bulk properties requires some sort of averaging. However, the selection of the averaging method is not arbitrary, but dependent on the purpose for which the averages are developed [36]. The bulk isentropic efficiency is defined using mass-averaged (ma) and work-averaged (wa) properties:

$$
\eta_{\mathrm{wa}}=\frac{T_{0, i n}^{\mathrm{ma}}-T_{0, e x i t}^{\mathrm{ma}}}{T_{0, i n}^{\mathrm{ma}}\left(1-\left(\frac{p_{0, \text { exit }}^{\mathrm{wa}}}{p_{0, \text { wa }}^{\mathrm{wa}}}\right)^{\frac{\gamma-1}{\gamma}}\right)}
$$

The properties at the turbine inlet (plane in) and outlet (plane exit) are mass-averaged over a PDC cycle using the following equation:

$$
\Phi_{\text {in/exit }}^{\operatorname{ma}}=\frac{\int_{0}^{\tau} \Phi \int_{A_{\text {in } / \text { exit }}} \rho u d A d t}{\int_{0}^{\tau} \int_{A_{\text {in/exit }}} \rho u d A d t}
$$


150

In equation (2), $\Phi$ represents the instantaneous mass-weighted average property at the inlet (in) or exit turbine planes,

$$
\Phi=\frac{\int_{A_{\text {in } / \text { exit }}} \phi \rho u d A}{\int_{A_{\text {in/exit }}} \rho u d A}
$$

where $\phi$ should be replaced by the appropriate property (e.g. temperature, $T_{0}$, total enthalpy, $h_{0}$, and ratio of specific heats, $\gamma$ ). This is the most adequate way of averaging temperature and enthalpy since it ensures the conservation of energy flux into the system [36, 13]. The instantaneous mass-weighted average properties are not to be confused with cycle massaverage properties (denoted by ma), as the later represents the average over an entire pulsed detonation cycle.

The pressure field is work-averaged and based on the definition of a uniform pressure field that preserves the work input $[36,23,13]$,

$$
\left(p_{0, i n}^{\mathrm{wa}}\right)^{\frac{\gamma-1}{\gamma}}=\frac{\int_{0}^{\tau} \int_{A_{i n}} \rho u T_{0} d A d t}{\int_{0}^{\tau} \int_{A_{i n}} \rho u\left(\frac{T_{0}}{\left(p_{0}\right)^{\frac{\gamma-1}{\gamma}}}\right) d A d t}
$$

and output [23],

$$
\left(p_{0, \text { exit }}^{\mathrm{wa}}\right)^{\frac{\gamma-1}{\gamma}}=\frac{1}{\tau\left|A_{\text {exit }}\right|} \int_{0}^{\tau} \int_{A_{\text {exit }}}\left(p_{0}\right)^{\frac{\gamma-1}{\gamma}} d A d t
$$

The cycle mass-averaged specific work is given by:

$$
w_{\mathrm{ma}}=h_{0, i n}^{\mathrm{ma}}-h_{0, \text { exit }}^{\mathrm{ma}}
$$

The cycle mass-averaged stage loading, $\psi$, is calculated as the ratio of the cycle massaveraged specific work with the square of blade speed:

$$
\psi_{\mathrm{ma}}=\frac{w_{\mathrm{ma}}}{U^{2}}
$$

The cycle mass-averaged rotor incidence angle, $\beta_{2, \mathrm{ma}}$, and cycle mass-averaged stator outlet angle, $\alpha_{2, \mathrm{ma}}$, are calculated at the stator-rotor interface,

$$
\Phi_{\text {interface }}^{\mathrm{ma}}=\frac{\int_{0}^{\tau} \Phi \int_{A_{\text {interface }}} \rho u d A d t}{\int_{0}^{\tau} \int_{A_{\text {interface }}} \rho u d A d t}
$$

${ }_{156}$ The mass balance is calculated over a period to check for mass conservation.

$$
\Delta_{m}=\int_{0}^{\tau} \int_{A_{i n}} \rho u d A d t-\int_{0}^{\tau} \int_{A_{\text {exit }}} \rho u d A d t
$$




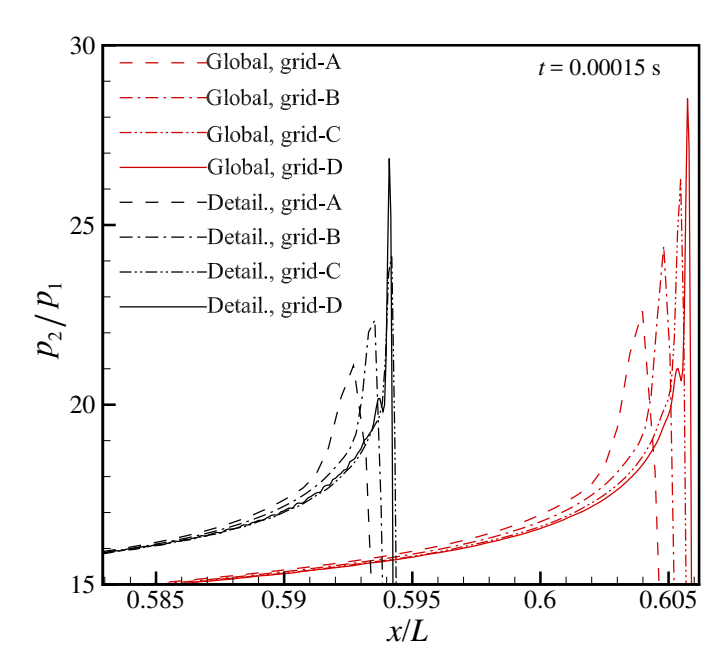

(a)

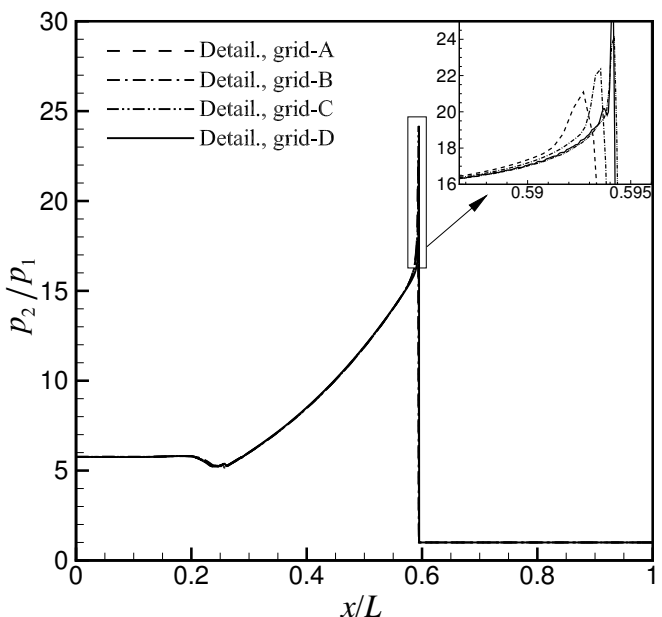

(b)

b)

Figure 3: Instantaneous pressure ratio distribution in the detonation tube at $t=0.00015$ s. a) Comparison between the detailed and global mechanism. b) Results obtained with the detailed mechanism.

\section{Performance of a single PDC-tube}

In this section an accurate and robust model is selected and validated against analytically predicted detonation properties. A partial view of the tube geometry $(R=0.02 \mathrm{~m}, L=$ $0.5 \mathrm{~m}$ ) is illustrated in Figure 1. The figure also shows the imposed boundary conditions as well as the initial conditions prior to detonation. The tube is closed at its left end, whereas the right end is open allowing for the fluid to discharge to a tank of large dimensions. The tank is represented by a domain with length equal to $5 L$ and radius equal to $50 R$. The tube is filled with a stoichiometric mixture of hydrogen and air at $p=1 \mathrm{~atm}$ and $T=300 \mathrm{~K}$, while the outer domain is filled only with air at similar conditions. 
$0.25 \mathrm{~mm}$; grid-B, $\Delta x=0.125 \mathrm{~mm}$; grid-C, $\Delta x=0.0625 \mathrm{~mm}$; grid-D, $\Delta x=0.03125 \mathrm{~mm}$. Regarding time-step, a maximum allowed physical time-step for each grid is found to be in the range of $10^{-8} \mathrm{~s}$ to $10^{-7} \mathrm{~s}$. This range provides reasonably accurate results without the occurrence of numerical instabilities. Moreover, it gives a good compromise between accuracy and computational time and it is in the acceptable range for the computation of the PDC-turbine test case.

The instantaneous pressure ratio distributions in the tube at $t=0.00015 \mathrm{~s}$, obtained with the global and detailed mechanisms, are compared in Fig. 3-a). The results show that the global mechanism predicts, in all grids, a higher detonation wave propagation velocity, and a higher von-Neumann peak pressure. Figure 3-b) shows the pressure ratio distribution computed with the detailed mechanism in different grids along the entire tube length. The results indicate that refining the grid provides a sharper resolution of the shock wave, but does not provide any further improvement in computing the post-shock conditions. Moreover, Fig. 3-a) shows that the usage of grid-D and the global mechanism might result in overshooting the analytically computed von-Neumann peak pressure of $27 \mathrm{~atm}$. In Table 1 the results obtained with grid-B for the detonation wave velocity are compared with results obtained with the NASA Chemical Equilibrium with Applications code (CEA) [37]. The deviation of the computed wave speed, relative to the analytically obtained solution is also listed in Table 1. The comparison shows that the detailed mechanism is more accurate when predicting the detonation wave velocity. The results obtained in grid-B, using a time-step of $5 \times 10^{-8}$, show a good compromise between accuracy, computation time and stability. Therefore, grid-B is selected together with the detailed finite-rate mechanism for the PDCturbine computation.

\section{Performance of the PDC-Turbine Stage}

In this section the results obtained from a two-dimensional turbine stage computation, coupled with a pulse detonation combustor, are presented and discussed. In low hub/tip radius ratio stages, three-dimensional effects may account for a significant portion of the stage losses. At the same time, in high hub/tip radius ratio turbines (e.g. high-pressure turbines) 
Table 1: Comparison of the computed global and detailed mechanisms in grid-B with the CEA [37] and analytical [38] results.

\begin{tabular}{lll}
\hline & $D_{\mathrm{CJ}}(\mathrm{m} / \mathrm{s})$ & $\epsilon_{D_{\mathrm{CJ}}}$ \\
\hline Global mech. & 2015 & $2.5 \%$ \\
Detailed mech. & 1945 & $1 \%$ \\
CEA & 1965 & - \\
\hline
\end{tabular}

radial velocities are normally modest, and if tip-leakage and endwall flows are neglected, the flow may be approximated as two-dimensional. However, if the turbine stage or operating conditions are prone to cause flow separation, neglecting three-dimensional effects will result in an underestimation of losses, and consequently an overestimation of stage performance. Computing turbulent flow including the chemical reactions necessary to simulate detonating combustion requires extremely refined grids in the direction of detonation wave propagation. At the same time, the chemical time-scales require extremely small advances in computational time. These restrictions lead to prohibitive computation time if three-dimensional flow is considered. Still, it is anticipated that the pulse detonation flow will cause strong variations in momentum in the two-dimensional plane. The impact of such variations in the turbine flow-field and on efficiency should be estimated first before considering the effects of three-dimensional secondary flows. Moreover, the estimation of two-dimensional flow provides a first insight into some of the major loss mechanisms occurring in PDC-turbines, i.e. flow separation and shock induced losses.

The next section gives details about the geometry and boundary conditions. Afterwards, the results obtained for the grid independence study are presented and the strategy to ensure convergence is discussed. The result section is divided into two subsections. First, the PDCturbine cycle averaged properties are analyzed to establish performance data for the turbine operating under different purge fractions. Afterwards, the PDC-turbine instantaneous flow behaviour is investigated in detailed, by analyzing the time-histories of different properties and also its variation of purge fraction and blade speed. 
Table 2: Geometrical data and operating conditions for the Graz transonic turbine stage and 2D model at rotor mid-span.

\begin{tabular}{lll}
\hline & Annular & 2D linear \\
\hline Stator pitch & $15^{\circ}$ & $60.94 \mathrm{~mm}$ \\
Stator axial chord & $56.3 \mathrm{~mm}$ & $56.3 \mathrm{~mm}$ \\
Stator chord & $81 \mathrm{~mm}$ & $81 \mathrm{~mm}$ \\
Geom. turning angle stator & $70^{\circ}$ & $70^{\circ}$ \\
Rotor pitch & $10^{\circ}$ & $40.63 \mathrm{~mm}$ \\
Rotor axial chord & $46.8 \mathrm{~mm}$ & $46.8 \mathrm{~mm}$ \\
Rotor chord & $55.9 \mathrm{~mm}$ & $55.9 \mathrm{~mm}$ \\
Geom. turning angle rotor & $107^{\circ}$ & $107^{\circ}$ \\
Stator rotor spacing & $27.5 \mathrm{~mm}$ & $27.5 \mathrm{~mm}$ \\
Detonation tube height, $h$ & - & $38 \mathrm{~mm}$ \\
Tube stator spacing, $a$ & - & $30 \mathrm{~mm}$ \\
Pressure ratio, $\pi$ & 3.5 & - \\
Rotational speed (rpm) & 10,500 & - \\
Inlet total temperature & $402 \mathrm{~K}$ & - \\
\hline
\end{tabular}

\subsection{Geometry and boundary conditions}

Figure 2 shows the two-dimensional PDC-turbine model used in the present computations. The geometry is inspired by the work of [39, 40], and no special care is taken on selecting any of the geometrical parameters. It comprises two detonation tubes coupled with a transonic turbine stage that was experimentally tested at Graz University in dry-air and steady inlet conditions. The Graz turbine geometry was selected primarily because it is a public available geometry. Such feature brings in the benefit of repeatability and allows for other researchers within the field to further elaborate on the presented work. The turbine stage vane and blade 2D sections are extracted at rotor mid-span. Details about the full annular configuration can be found in $[24,25]$ and additional details about the turbine stage and 2D linear model are listed in Table 2. The simulation of the PDC-turbine system 
includes the typical sequential processes of a pulse detonation cycle, as illustrated in Fig. 4. During the fill process, a uniform mixture of fuel and air is injected at the valve plane (Fig. 4-a). During this process the valve is completely open. Afterwards, the valve is closed and a shock induced mechanism is used to initiate detonation at the left end of the tube (Fig. 4-b). During propagation, the detonation wave travels towards the right end of the tube, increasing pressure and temperature as the fuel-air mixture is consumed (Fig. 4-c). The blowdown process is initiated when the detonation wave leaves the tube, creating an expansion wave that propagates towards the closed end of the tube starting the exhaust process (Fig. 4-d), until the initial (purge) static pressure is reached (Fig. 4-e). The final process is the injection of purge air, which is used to completely or partially purge the tube of the hot products of detonation (Fig. 4-f). The purge flow acts as a buffer, preventing pre-detonation of the subsequently injected fuel-air mixture and can also be used to control the cycle mass-averaged outlet temperature.

The boundary conditions for the different cycle phases are given in Table 3. A variable boundary condition is employed at the valve to simulate the aforementioned PDC processes. It specifies total pressure, total temperature and mass fraction of species during fill and purge, shifting instantaneously into a wall condition during detonation propagation and blowdown. At the outlet, a constant static pressure is specified when the flow is subsonic, and pressure is extrapolated from the numerical domain when the flow is supersonic. In the detonation tube and turbine walls a non-slip boundary condition is imposed. Again, a trigger gas is used to start detonation in the closed end of the tube $\left(p_{\mathrm{tr}}=60 p_{\text {in }}, T_{\mathrm{tr}}=3000 \mathrm{~K}\right)$. Regarding the time-step, it also varies for the different PDC processes. During fill and purge a time-step ranging from $2.80 \times 10^{-6} \mathrm{~s}$ to $4.76 \times 10^{-6} \mathrm{~s}$, is used for the higher and lower rotor speeds, respectively. During detonation propagation and blowdown a time-step of $5 \times 10^{-8} \mathrm{~s}$ is employed to resolve the chemistry time-scales.

\subsection{Numerical grid and convergence check}

The stage blade-count ratio is 2:3 simplifying the creation of the numerical grid, which is composed of three independent domains. Two domains are stationary, comprising the 


\begin{tabular}{|c|c|c|}
\hline $\begin{array}{l}T_{0, i n} \\
p_{0, i n}\end{array}$ & $T_{1} \gamma_{1} p_{1}$ & Reactants \\
\hline
\end{tabular}

a)

Detonation Initiation (trigger region)

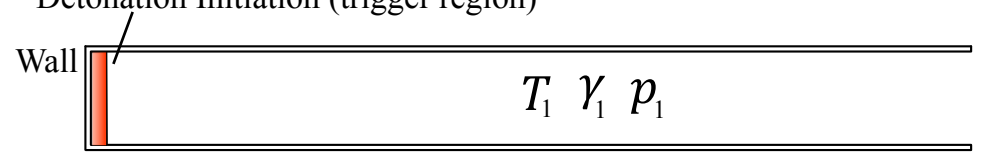

b)

Wall \begin{tabular}{|lllll}
\hline \multicolumn{1}{|c}{$T_{2}$} & $\gamma_{2}$ & $p_{2}$ & \multicolumn{2}{c}{ Detonation Front propagation } \\
\hline
\end{tabular}

c)

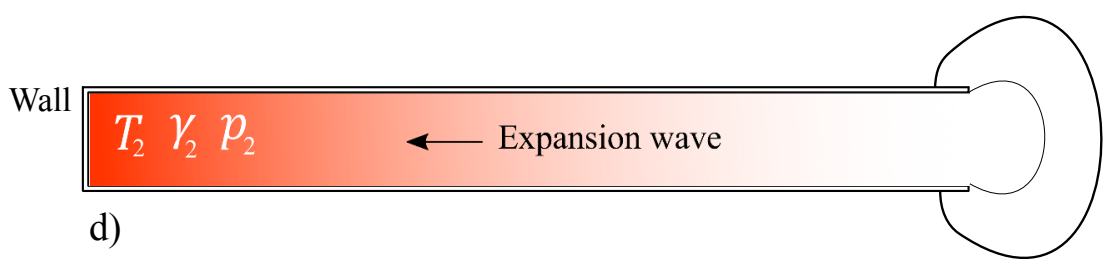

\section{Products}

e)

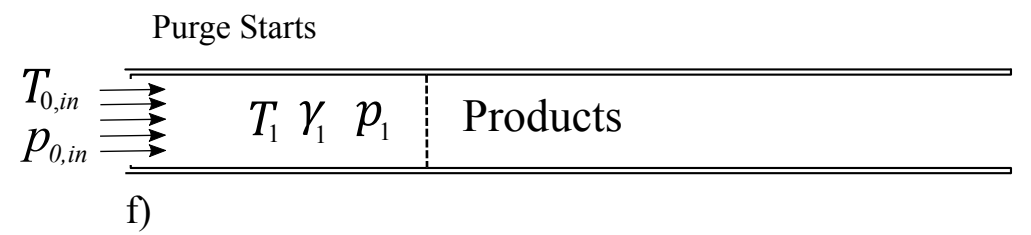

Figure 4: Different phases occurring in a PDC cycle [3]: a) filling ends; b-e) detonation initiation, propagation and blowdown; f) purge starts. 
Table 3: Boundary conditions specified during the pulsed detonation combustion cycle. The mass fractions for the trigger phase are specified in the trigger region $L_{t r}=0.005 \mathrm{~L}$.

\begin{tabular}{llllllll}
\hline & $\mathrm{H}_{2}{ }^{\mathrm{a}}$ & $\mathrm{O}_{2}{ }^{\mathrm{a}}$ & $\mathrm{H}_{2} \mathrm{O}^{\mathrm{a}}$ & $\mathrm{N}_{2}$ & $p_{0, \text { in }}{ }^{\mathrm{b}}$ & $T_{0, \text { in }}{ }^{\mathrm{c}}$ & $p_{\text {out }}{ }^{\mathrm{b}}$ \\
\hline Fill & 0.0283 & 0.204 & 0 & 0.767 & 3.4 & 403 & 0.935 \\
Purge & 0 & 0.233 & 0 & 0.767 & 3.4 & 403 & 0.935 \\
Det. & Wall & Wall & Wall & Wall & Wall & Wall & 0.935 \\
Trig. & $0^{\mathrm{d}}$ & $0^{\mathrm{d}}$ & $0.232^{\mathrm{d}}$ & $0.767^{\mathrm{d}}$ & Wall & Wall & 0.935 \\
\hline
\end{tabular}

${ }^{a}$ Values are in mass fraction

b Values are in bar

${ }^{\mathrm{c}}$ Values are in $\mathrm{K}$

${ }^{\mathrm{d}}$ In the trigger region

detonation tubes and two stator passages. The third domain includes three rotor blades and it is moving at a constant translational velocity, $U$, in the positive $y$-axis direction. For the turbine stage walls, the first cell is located at a distance that ensures a $y^{+}<1$ for the entire range of operation of the PDC cycle. In the detonation tube, one needs to ensure that enough cells are positioned in the direction of detonation wave propagation. The axial distance of the cells is thus set to $\Delta x=0.125 \mathrm{~mm}$.

A grid sensitivity study was performed in order to reach a final solution independent of mesh size. Three different grids of increasing resolution are investigated: 142,000 cells; 492,565 cells; and 1,970,260 cells. Figure 5 shows the relative error for the mass-averaged total pressure and mass-flow rate, sampled at the stator-rotor interface. The results show that the error magnitude decreases with grid refinement, and that the relative difference in mass flow rate and total pressure, between the refined and medium size grid is lower than $0.05 \%$. The medium size grid is therefore selected for the remaining PDC-turbine computations.

Time convergence is confirmed by analyzing the time-variation of different properties at the turbine inlet and outlet planes, and ensuring that a periodic solution is obtained. Figure 6 shows the static pressure time history sampled at plane in. One can verify that 


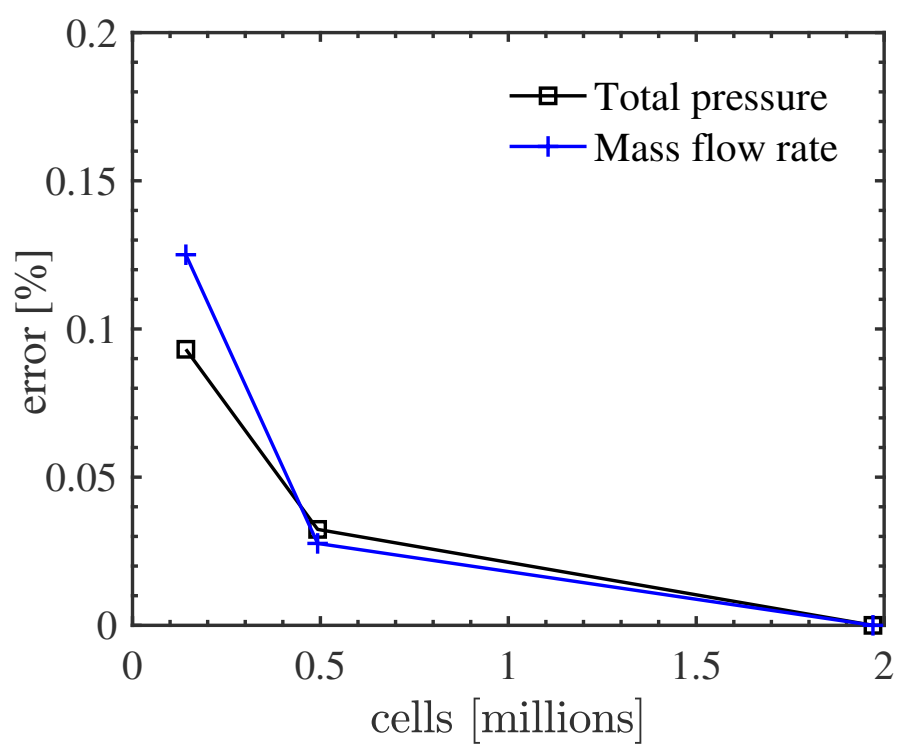

Figure 5: Relative error computed for the mass-flow rate and total pressure at stator-rotor interface.

a time periodic solution is obtained after four PDC cycles. Therefore, all cases are allowed to run for at least 4 cycles before any data is extracted. The mass balance over a period is calculated using equation (9) and also used for convergence check.

\subsection{Results}

The supersonic nature of detonation combustion generates high amplitude pressure fluctuations during the active detonation phase of the PDC cycle. Figure 7 shows the timehistory of the mass-weighted averaged static pressure during one pulse detonation cycle,

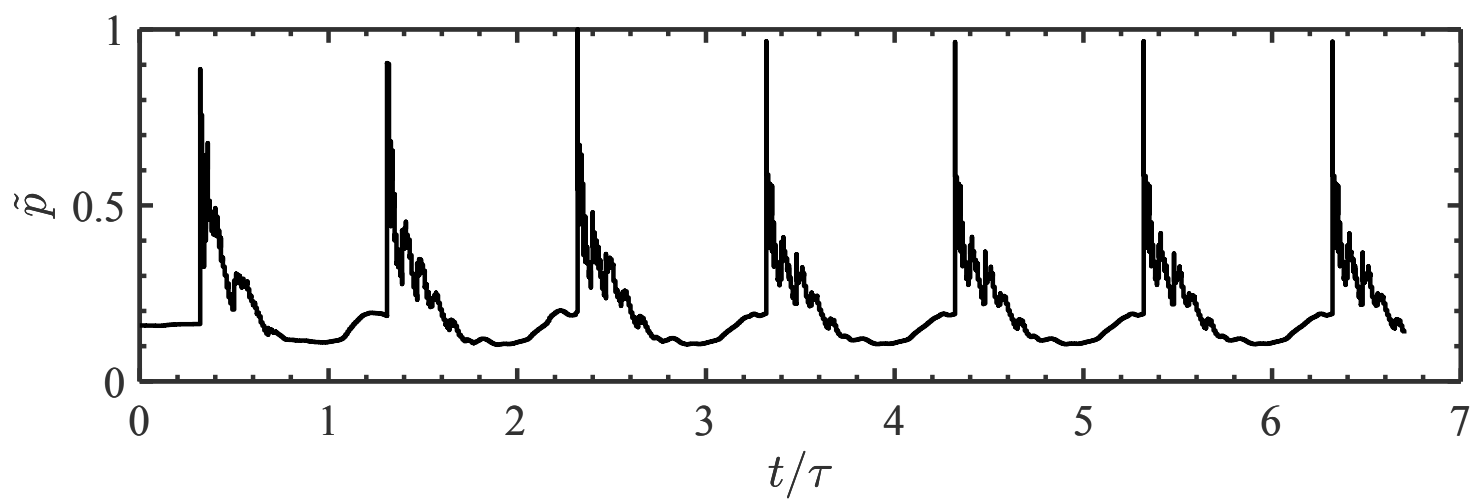

Figure 6: Static pressure history sampled at the turbine inlet during the first seven periods of simulation. 
sampled at the turbine inlet plane $(i n)$. The figure also shows the behavior of isobars at different time instances. At time instance $\mathbf{A}$ one can observe the propagation of the detonation wave, increasing pressure and temperature, as the fuel-air mixture is combusted. The detonation wave is followed by an expansion wave as the flow is decelerated from the Chapman-Jouguet (CJ) state to stagnation at the valve plane. A complex shockwave pattern travels through the stator vanes at time instance $\mathbf{B}$. At the same time instance, it is possible to observe the creation of an upstream non-stationary bow-shock. The interaction between the shockwaves and the boundary layer may lead to the creation of localized separation bubbles in the stator vanes, or even complete separation of the boundary layer. These phenomena will be responsible for increasing the boundary layer losses, see Fig.8. The same phenomena occur in the rotor blades as the non-stationary shockwaves travel in the rotor domain at time-instance $\mathbf{C}$, where one can also observe a pressure wave reflected towards the tubes. At time-instance $\mathbf{D}$, the first reflected wave arrives at the turbine inlet and is ingested by the stage, carrying with it a portion of the combustion products. The final stage of detonation is represented by time-instance $\mathbf{E}$, where the products of detonation are ingested by the turbine until the pressure in the tubes is lower than the inlet total pressure. This is the most stable period of the detonation phase, where temperature is gradually decreasing without the occurrence of significant pressure waves. The detonation phase is preceded/followed by the purge and fill phases, where colder flow is injected at the tube valve section in the form of purge air or fuel-air mixture. The turbine is therefore subjected to an unbalanced flow-field over the entire PDC period with unique features and associated losses. The purpose of the present work is to identify possible trade-offs likely to be necessary to balance the work output with stage efficiency. Such trade-offs can be identified by varying a cycle parameter (purge-fraction) and analyzing the behavior of the flow-field and loss mechanisms.

In the present study the effect of purge fraction,

$$
f=\frac{t_{p}}{t_{f}+t_{p}}
$$

given by the relation between purge and valve opening time, is analyzed for different rotor 

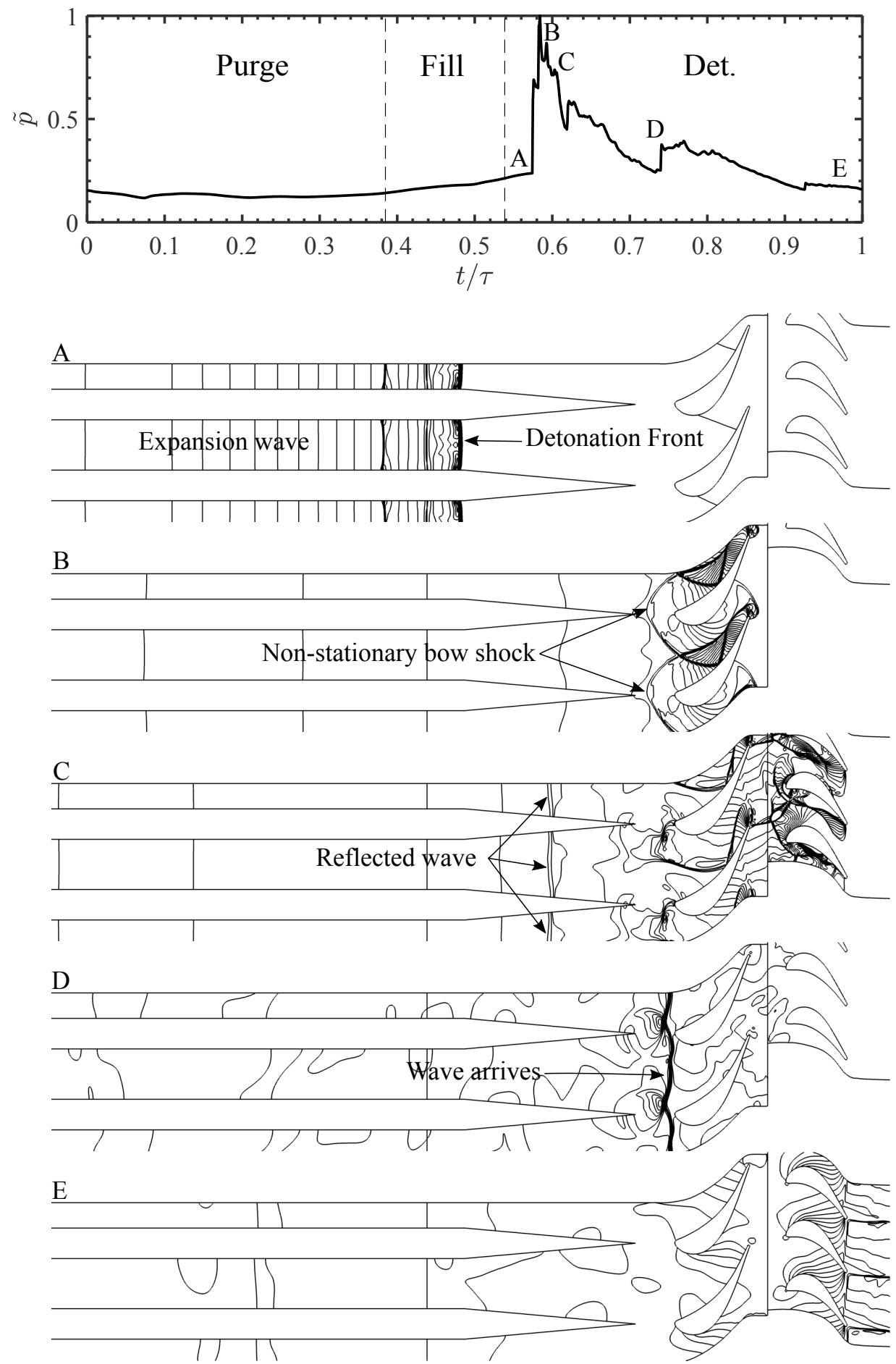

Figure 7: Mass-weighted averaged static pressure history sampled at plane in. The figure also shows instantaneous isobar lines illustrating the complex shockwave structure occurring in the rotor and stator domains. 


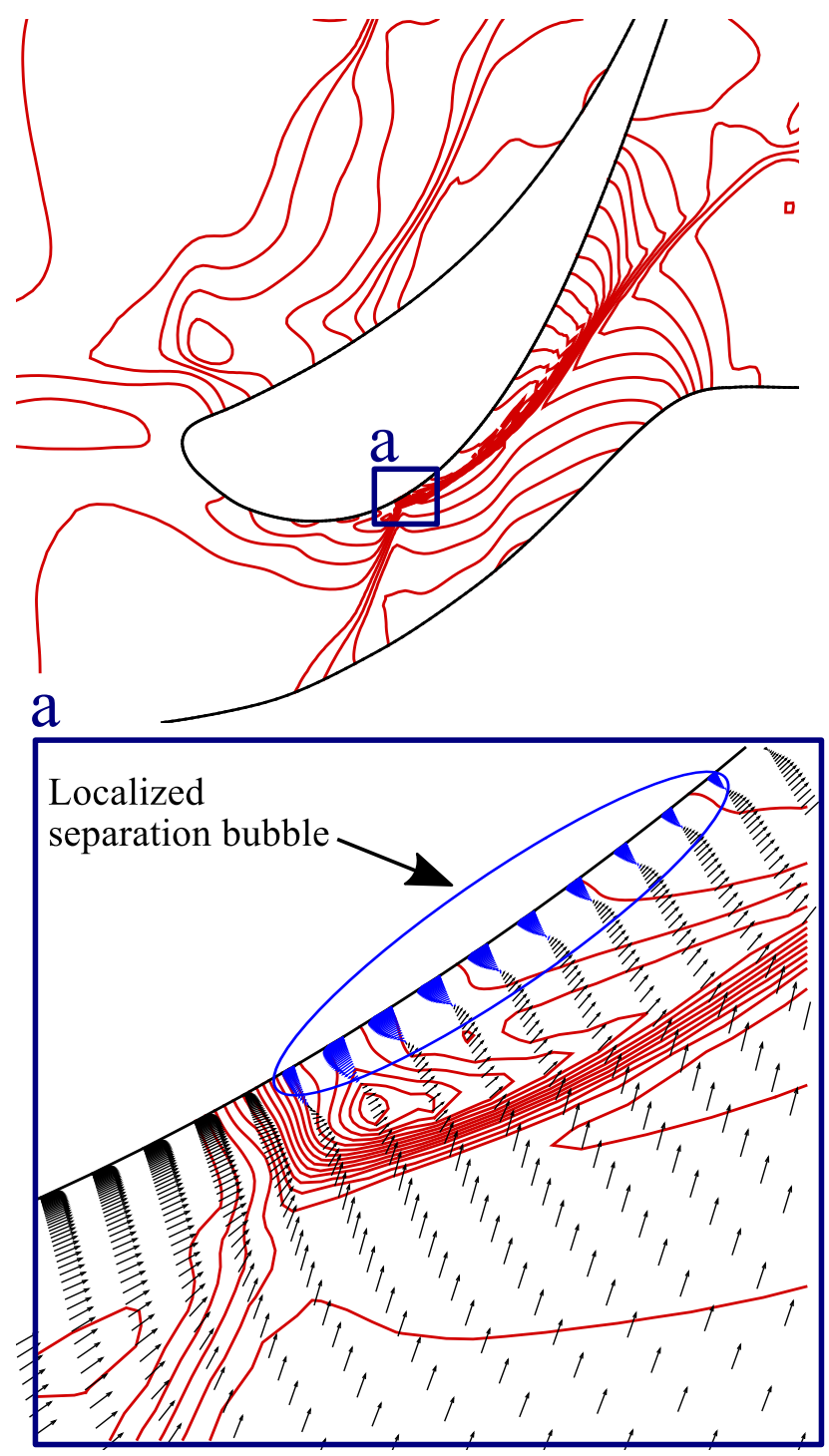

Figure 8: Shock wave interaction with the nozzle suction side boundary layer causing a localized separation zone. This flow behaviour is observed between time instances B and C of Fig.7. The isobar lines are shown in red, the velocity vectors in black, and the separation bubble velocity vectors in blue. 


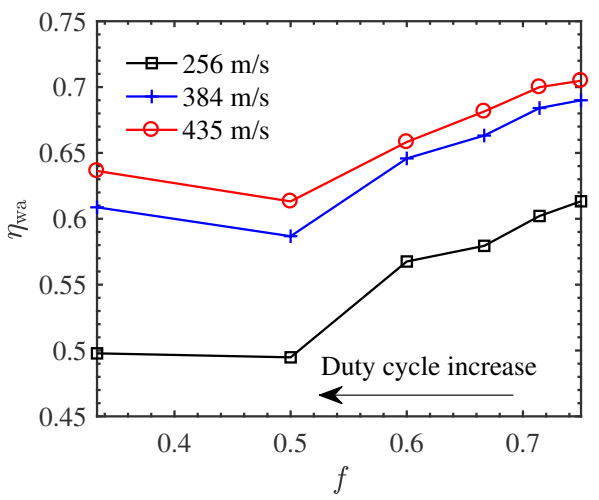

(a)

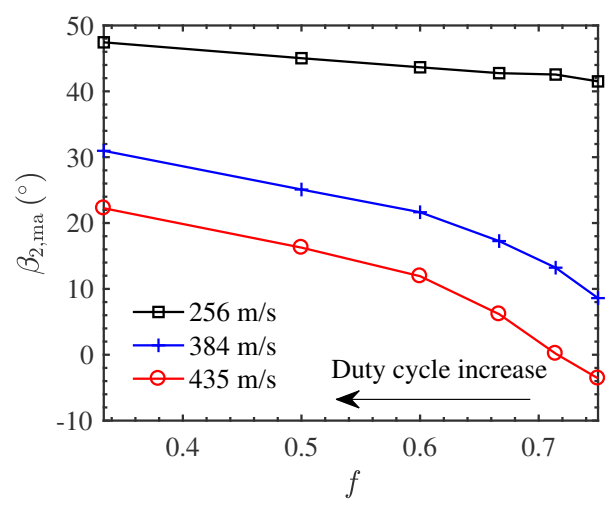

(c)

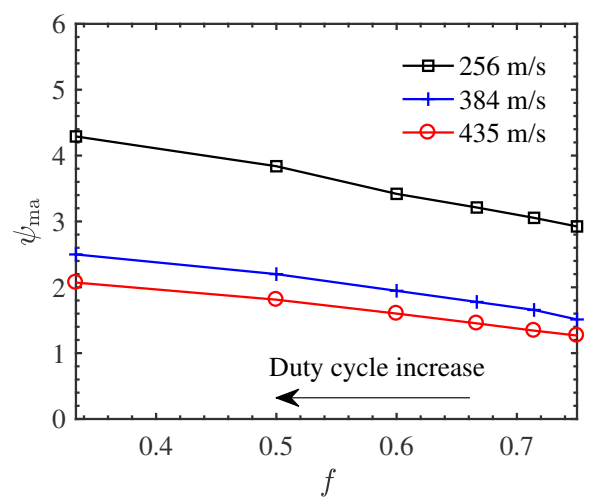

(e)

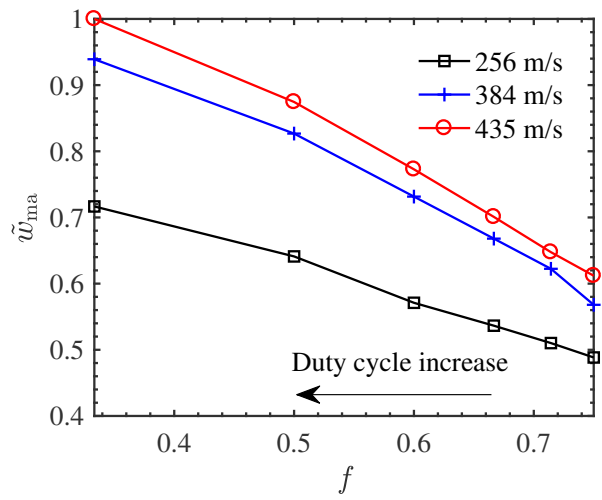

(b)

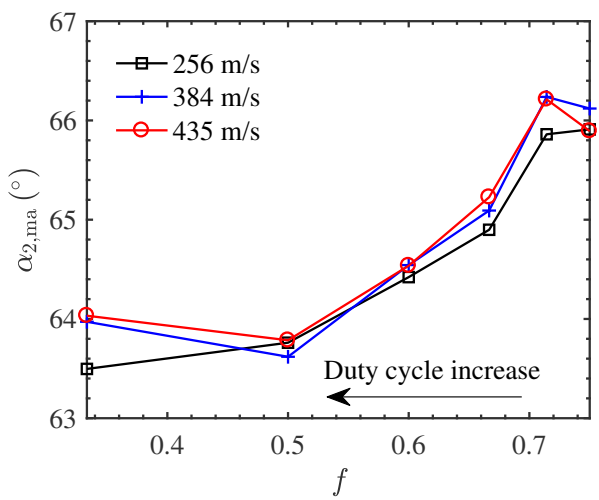

(d)

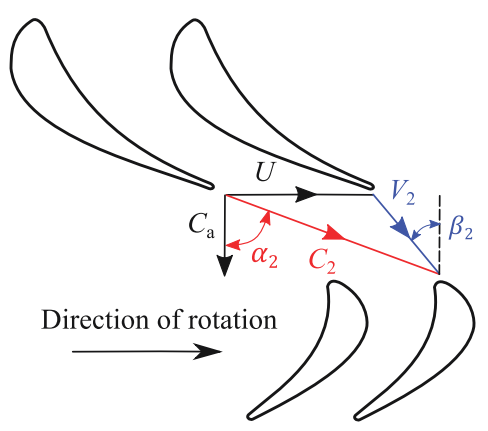

(f)

Figure 9: a) Work-averaged isentropic efficiency vs purge fraction; b) Normalized cycle mass-averaged work vs purge fraction; c) Cycle mass-averaged rotor incidence angle vs purge fraction; d) Cycle mass-averaged stator exit angle vs purge fraction. e) Cycle mass-averaged stage loading vs purge fraction. f) Angle definition used at stator-rotor interface, $C_{a}$ is the axial velocity, $C_{2}$ is the absolute velocity and $V_{2}$ is the relative velocity. 
speeds $(U=256 \mathrm{~m} / \mathrm{s} ; U=384 \mathrm{~m} / \mathrm{s} ; U=435 \mathrm{~m} / \mathrm{s})$. Purge fraction can also be calculated in terms of volume or mass ratios. For the present investigation, only synchronized firing was considered, hence all phases of the detonation cycle occur simultaneously in all tubes. Therefore, purge fraction in terms of time-ratio gives a good approximation to mass-ratio. The purge fraction is modified by varying the purge time, $t_{p}$ while keeping the filling time, $t_{f}=1 \mathrm{~ms}$ constant. The test cases considered in the present analysis are listed in Table 4 .

Table 4: Different purge fractions considered in the current analysis.

\begin{tabular}{lllllll}
\hline & PG1 & PG2 & PG3 & PG4 & PG5 & PG6 \\
\hline$f$ & $1 / 3$ & $1 / 2$ & $3 / 5$ & $2 / 3$ & $5 / 7$ & $3 / 4$ \\
$t_{p}(\mathrm{~ms})$ & 0.5 & 1 & 1.5 & 2 & 2.5 & 3 \\
\hline
\end{tabular}

\subsubsection{Cycle averaged properties}

Figure 9-a) shows the variation of the cycle work-averaged turbine efficiency, $\eta_{\text {wa }}$, with purge fraction, $f$, for different rotor speeds. The plot shows that a decrease in purge fraction, down to $f=1 / 2$, results in a reduction in turbine efficiency. For constant fill and detonation times, a decrease in purge fraction leads to an increase in duty cycle or detonation frequency. This means that if a turbine design point is closer to purge conditions, increasing the detonation frequency will subject the turbine to operating under off-design conditions for a larger portion of the PDC cycle. At the same time, increasing the duty cycle is a necessary feature for increasing the cycle mass-averaged turbine work output, $w_{\text {ma }}$, see Fig. 9-b). It is noted that the work output is normalized by the maximum attained value for all the different rotor speeds. Regarding the effects of rotor speed, a $50 \%$ increase in rotor translational velocity leads to $22 \%$ and $14 \%$ increase in efficiency for the lower and higher purge fractions, respectively. This discrepancy is associated with the fact that increasing the duty cycle affects the cycle mass-averaged rotor incidence angle $\beta_{2 \text {,ma }}$, at different rates for different rotor speeds, see Fig. 9-c). For the lower rotor speeds, excessive incidence angles are observed during purge conditions. Such behavior can be identified by analyzing the time history of the rotor incidence angle for a single detonation cycle, see Fig. 10 upper plot. The 
angle definition used at the stator-rotor interface is given in Fig. 9-f), $C_{a}$ is the axial velocity, $C_{2}$ is the absolute velocity and $V_{2}$ is the relative velocity. The results obtained for the cycle work-averaged turbine efficiency also show a slight increase in performance in the lower end of purge fraction. It is believed that the reason behind such behaviour is the increased operating frequency and power input to the turbine (increase in cycle mass-averaged input temperature and pressure), this will be elaborated in the next subsection.

The normalized cycle mass-averaged work generated by the turbine is plotted in Fig. 9b), showing that increasing the rotor speed results in an increase in mass-averaged work production. However, the incidence angle (Fig. 9-c) and consequently the rotor turning angle also decreases with rotor speed, compromising the turbine capability for generating shaft torque. This effect is more pronounced at higher purge fractions, where the work generated increases by approximately $20 \%$ for a $50 \%$ increase in rotational speed. For lower purge fractions the work generated increases by $30 \%$ for the same increase in rotor speed. The cycle mass-averaged stator outlet angle, $\alpha_{2, \text { ma }}$, is almost insensitive to rotor speed and purge fraction, see Fig. 9-d). The cycle mass-averaged stage loading coefficient, $\psi_{\text {ma }}$, is plotted against purge fraction and rotational speed in Fig. 9-e). A decrease in rotational speed and purge fraction leads to an increase in mass-averaged rotor incidence angle, implying a larger turning angle and thus a higher stage loading coefficient.

\subsubsection{Instantaneous properties}

Figure 10 shows the time history of the mass-weighted averaged rotor incidence angle, $\beta_{2}$, normalized total temperature, $\tilde{T}_{0}$, and stator exit angle, $\alpha_{2}$. The plots shows the properties computed for a constant rotor speed of $256 \mathrm{~m} / \mathrm{s}$ and purge fraction of $f=5 / 7$ (PG5). The instantaneous mass-weighted averaged properties are calculated at stage inlet (in) and stage outlet (exit) planes. The relative instantaneous mass-weighted averaged velocities are calculated at the stator-rotor interface and are used to calculate the rotor inlet angle. The upper plot of Fig. 10 reveals an excessive rotor incidence angle during several phases of the detonation cycle, causing flow separation and further penalizing the stage efficiency. During fill it also shows a slight decrease in rotor incidence angle. This marks the arrival of the colder 

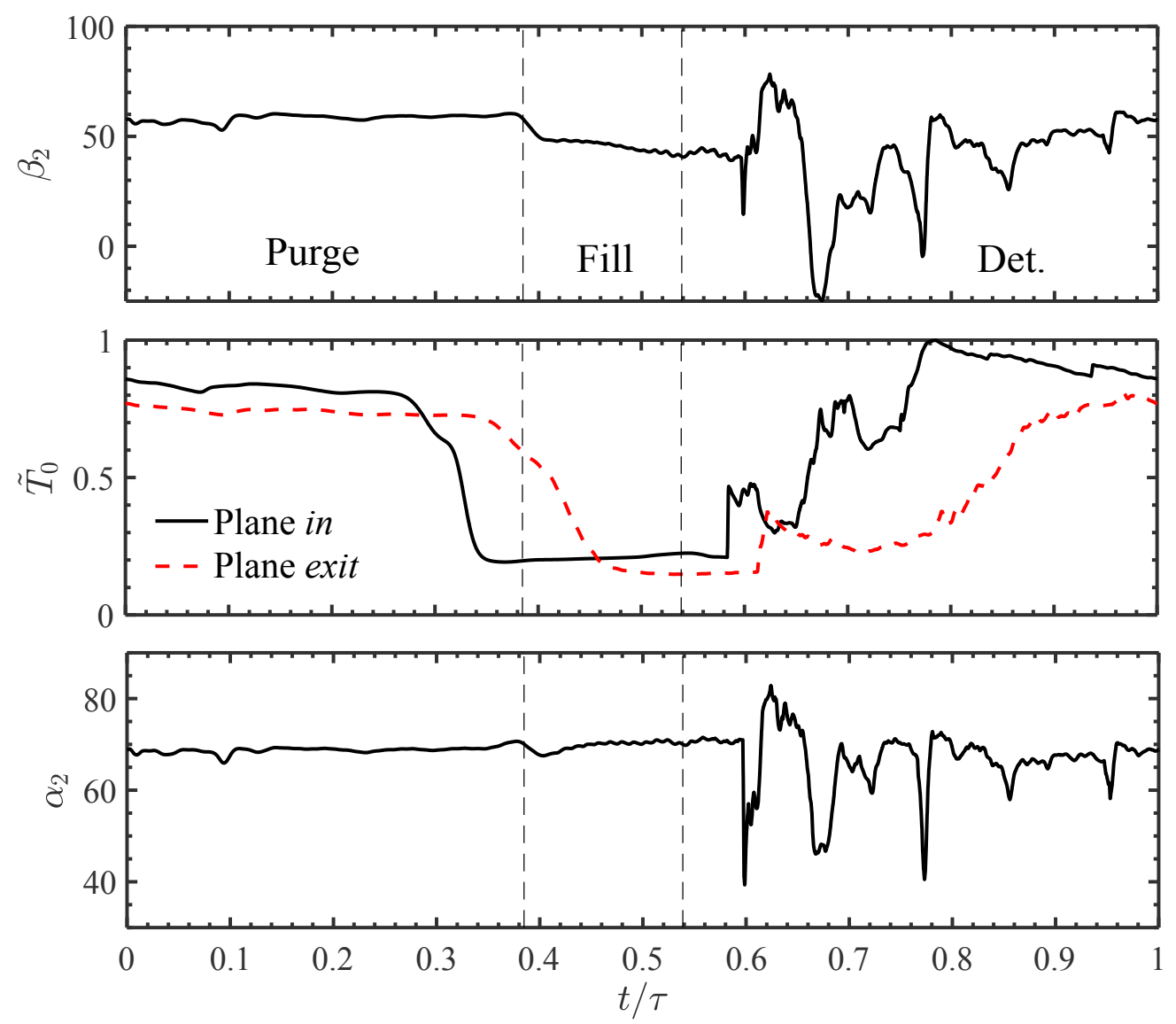

Figure 10: Time-history of mass-weighted averaged rotor incidence angle, $\beta_{2}$, normalized total temperature, $\tilde{T}_{0}$, and stator exit angle, $\alpha_{2}$; computed for a purge fraction of $f=5 / 7$ and rotor velocity of $256 \mathrm{~m} / \mathrm{s}$ (PG5-256).

purge air at the rotor inlet, reducing the speed of sound and relative velocities. The turning capability of the stator is not affected during purge and fill; therefore $\alpha_{2}$ remains almost constant (bottom plot in Fig. 10). During the detonation phase one can observe strong variations in both angles, which are responsible for large penalties in turbine efficiency.

The effects of rotor speed in the time history of the mass-weighted averaged rotor incidence angle, $\beta_{2}$, normalized total temperature, $\tilde{T}_{0}$, and stator exit angle, $\alpha_{2}$, can be observed by comparing Fig. 10 with Fig. 11. For a better comparison, the $\beta_{2}$ plot includes, in gray, the $\beta_{2}$ variation obtained for the case of reduced rotor speed (PG5-256, Fig. 10). The higher rotational speed in the PG5-435 test case leads to more favorable rotor incidence angles 
during purge, but generates negative incidence angles during detonation, reducing the stage loading and deteriorating the turbine's capability to generate shaft torque. As expected, the stator outlet angle and total temperature time histories are almost insensitive to a rotor speed increase from $256 \mathrm{~m} / \mathrm{s}$ to $435 \mathrm{~m} / \mathrm{s}$. The ratio between inlet and outlet total temperature slightly increases with rotor speed, due to an increase in efficiency and higher work output.

The time history of normalized total pressure, $\tilde{p}_{0}$, computed at stage inlet and exit planes is shown in Fig. 11 to support the evaluation of the peak pressure damping across the turbine. The pressure damping, $\Gamma$, across the stage can be calculated with the following expression:

$$
\Gamma=\frac{\operatorname{MinMax}_{i n}-\operatorname{MinMax}_{\text {exit }}}{\operatorname{MinMax}_{\text {in }}}
$$

where,

$$
\operatorname{MinMax}=\frac{\max \left[p_{0}(t)\right]-\min \left[p_{0}(t)\right]}{\operatorname{mean}\left[p_{0}(t)\right]}
$$

The damping of pressure across the stage is found to be $21 \%$ at low rotor speed, which is consistent with turbine studies performed in a turbine exposed to the fluctuations from a rotating detonation combustor [11], for which a damping of about $28 \%$ was identified. At higher rotational speeds the damping computed in the present simulation is increased to $39 \%$. A deeper analysis of the results reveals that most of the damping actually occurs through the vane passage.

The time-histories of Mach number, M, computed at the stage inlet plane and at the stator-rotor interface are also shown in Fig. 11. As the detonation front arrives at the inlet vane, the vane inlet Mach number peaks above one, causing an instantaneous choking of the flow. Therefore, there is an accumulation of mass flow which is then followed by the release of the mass during the expansion phase.

A closer inspection of the time-history of the flow streamlines, for the test case with higher blade speed (Fig. 11, PG5-435) is given in Fig. 12, allowing some mechanisms responsible for the penalization of efficiency and work output to be identified. It is noted that the labeling used in Fig. 12 (A-F) refers to Fig. 11 upper plot time instances. Figure 12 shows that 

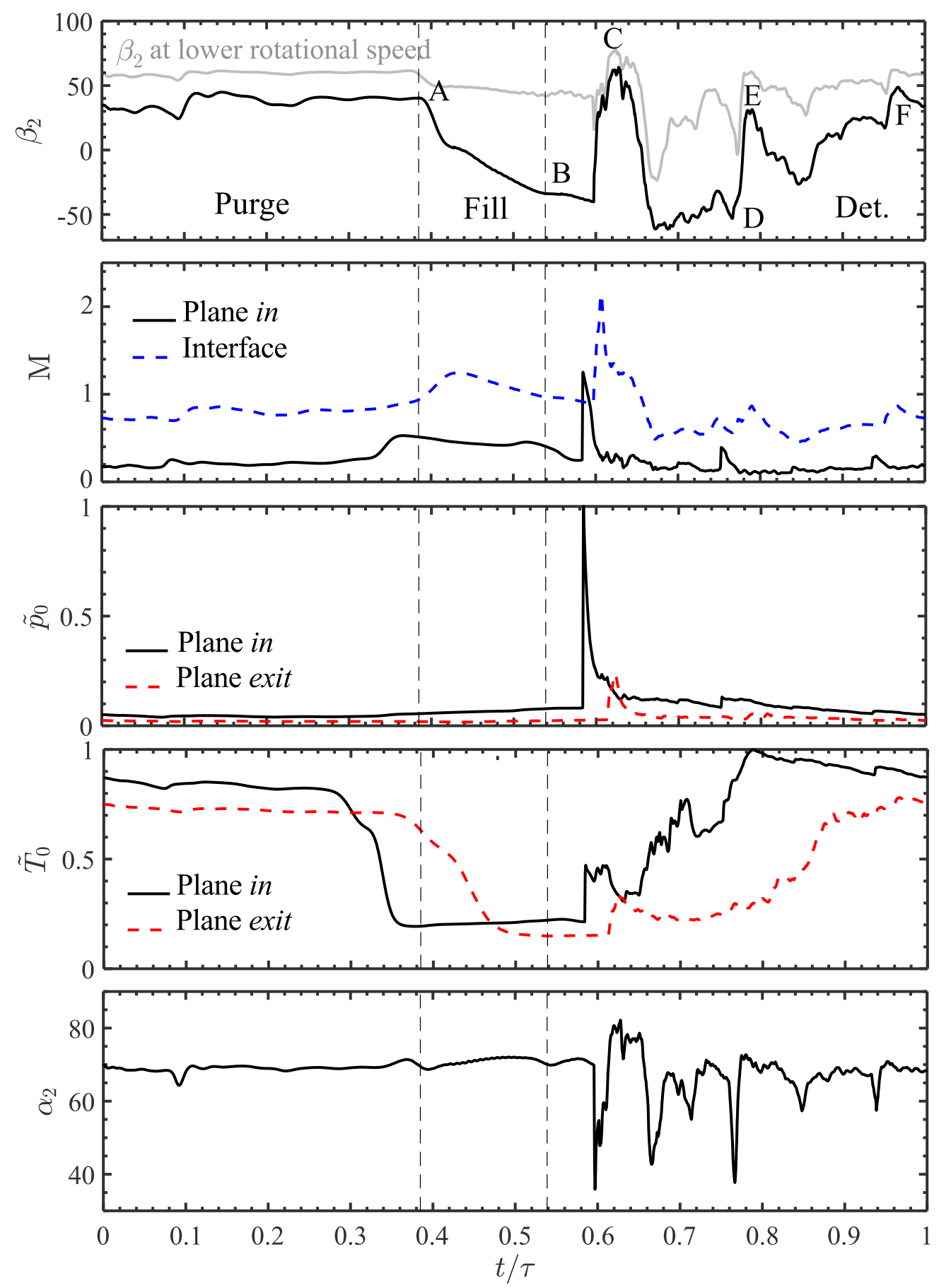

Figure 11: Time-history of mass-weighted averaged rotor incidence angle, $\beta_{2}$; Mach number, M; normalized total pressure, $\tilde{p}_{0}$; normalized total temperature, $\tilde{T}_{0}$; and stator exit angle, $\alpha_{2}$; computed for a purge fraction of $f=5 / 7$ and rotor velocity of $435 \mathrm{~m} / \mathrm{s}$ (PG5-435). 
during purge (instance $\mathbf{A}$ ) the hot products are entering the turbine at an angle close to design conditions, leading to a smooth turning of the flow. Instance $\mathbf{B}$ represents an instance of the fill period, where a portion of the cold purge flow enters the rotor domain, resulting in a decrease in speed of sound and relative velocities that leads to negative incidence angles and negative torque. When the first shockwave arrives at the rotor, at time instance $\mathbf{C}$, the excess in kinetic energy results in a sudden increase in Mach number and incidence angle, causing flow separation and increasing the stage losses. At instance $\mathbf{D}$, the hot products of detonation have not yet completely reached the stator-rotor interface, leading again to negative incidence angles. Instance $\mathbf{E}$, marks the arrival of a pressure wave, slightly increasing the kinetic energy, increasing the turbine pressure ratio, and carrying a portion of the hot gases that were trapped in the detonation tube. This will result in an inflexion of the rotor incidence angle, likely to cause subsequent flow separation and losses. During the last periods of the PDC cycle, here represented by time instance $\mathbf{F}$, the remaining hot products of detonation are ingested by the stage without the occurrence of significant pressure fluctuations or flow separation.

The variation of rotor inlet conditions (pressure, temperature, velocity field and mass flow) and consequent mismatch with the rotor speed, seems to be responsible for a reasonable amount of the losses arising in the PDC-turbine system and requires further investigation. Figure 13 shows the time history of rotor incidence angle for different purge fractions and for a constant rotor speed of $435 \mathrm{~m} / \mathrm{s}$. The results show that the behavior of rotor angle fluctuations, around the $\beta_{2}=0$, varies significantly with purge fraction. The aforementioned trend, leads to an increase in cycle mass-averaged $\beta_{2, \text { ma }}$, with decreasing purge fraction, as shown in Fig. 9-c). The plot also reveals that the fluctuations in incidence angle during detonation and blowdown are less severe for lower purge fractions (increase in duty cycle and power input). Such behaviour, is likely to be responsible for an increase in stage efficiency when the purge fraction is reduced from $1 / 2$ to $1 / 3$ (see Fig. 9a). It is noted that the fluctuations in incidence angle are affected by the fluctuations in thermodynamic properties. This behavior is illustrated in Fig. 14, where the normalized temperature history, sampled at planes in and exit, is plotted for different purge fractions and the same rotor speed. The plot 

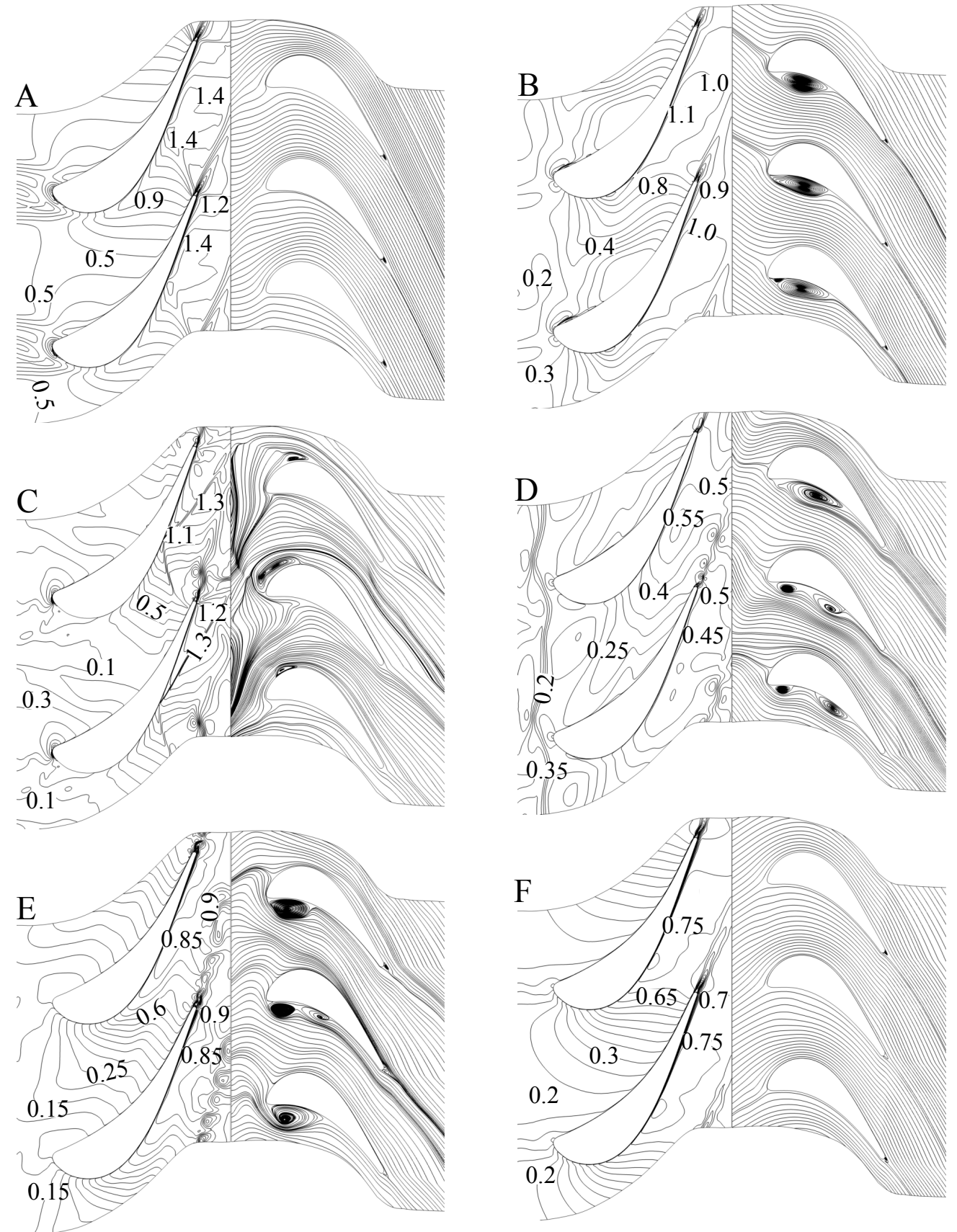

Figure 12: Mach numbers computed at the stator domain and relative streamlines computed at the rotor domain for a purge fraction of $f=5 / 7$ and rotor blade speed of $435 \mathrm{~m} / \mathrm{s}$ (PG5-435). 
shows that decreasing the purge fraction also decreases the number and average amplitudes of the temperature fluctuations and reveals a smoother transition between purge, fill and detonation phases.

The results plotted in Figs. 13-14 show that increasing the detonation duty cycle increases the cycle mass-average temperature (and pressure) and power input to the turbine. That will allow for the turbine nozzle to be choked during a bigger portion of the cycle and to reduce flow instabilities. The increased duty cycle will also result in a more uniform temperature field at the PDC outlet with the associated benefits in rotor incidence angle. Increasing the PDC inlet purge air and fuel-air mixture temperature and pressure should also allow for a similar effect, by reducing the amplitude of both temperature and rotor incidence angle variations.

\section{Conclusions}

In this paper a numerical study, using URANS simulations, of a coupled PDC-turbine system is reported in an attempt to identify the different loss mechanisms occurring in axial turbines under the influence of pulsed detonation combustion flow. The URANS solver was coupled with a detailed chemistry mechanism for simulating detonation flow in stoichiometric hydrogen-air mixtures.

The results allowed the identification of different loss mechanisms. The occurrence and traveling of non-stationary shockwaves across the stage are responsible for the creation of localized separation bubbles in the nozzle vanes and rotor blades. The complex shockwave pattern is, therefore, expected to increase the boundary layer losses in every PDC cycle and should also be the source of unwanted vibrations. The mismatch between the constant blade speed and time-dependent rotor inlet conditions resulted in strong periodic variations of incidence angle. Such variations were identified as the cause for both flow separation and periods of negligible or even negative torque. Such behaviour is believed to be responsible for a reasonable amount of losses arising in the present PDC-turbine system. For this particular turbine design, it is also observed that the stage operates more efficiently under purge conditions. This implies that a change to a more favorable blade angle could improve 

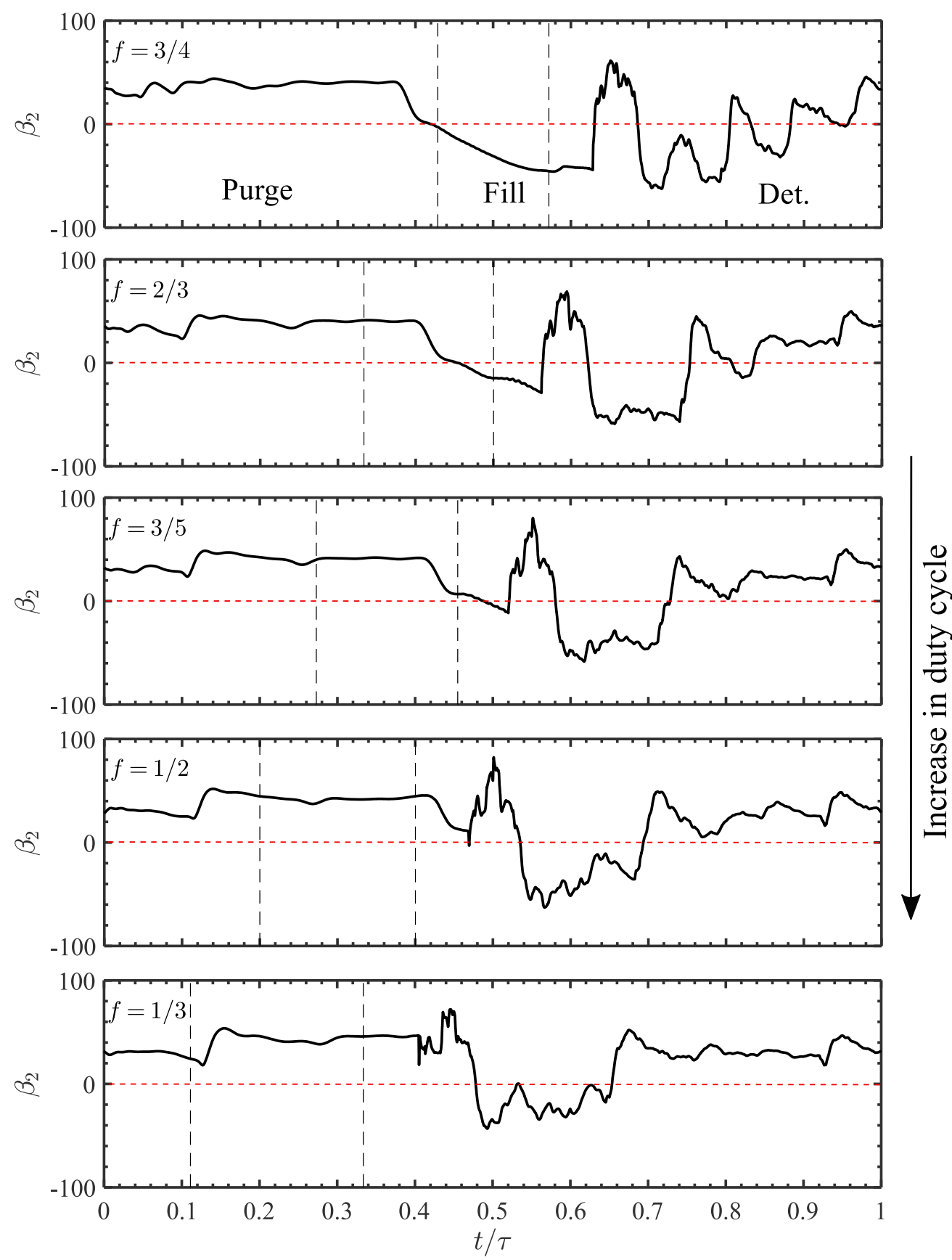

Figure 13: Variation of rotor incidence angle time history with purge fraction for a constant rotor blade speed of $435 \mathrm{~m} / \mathrm{s}$. 

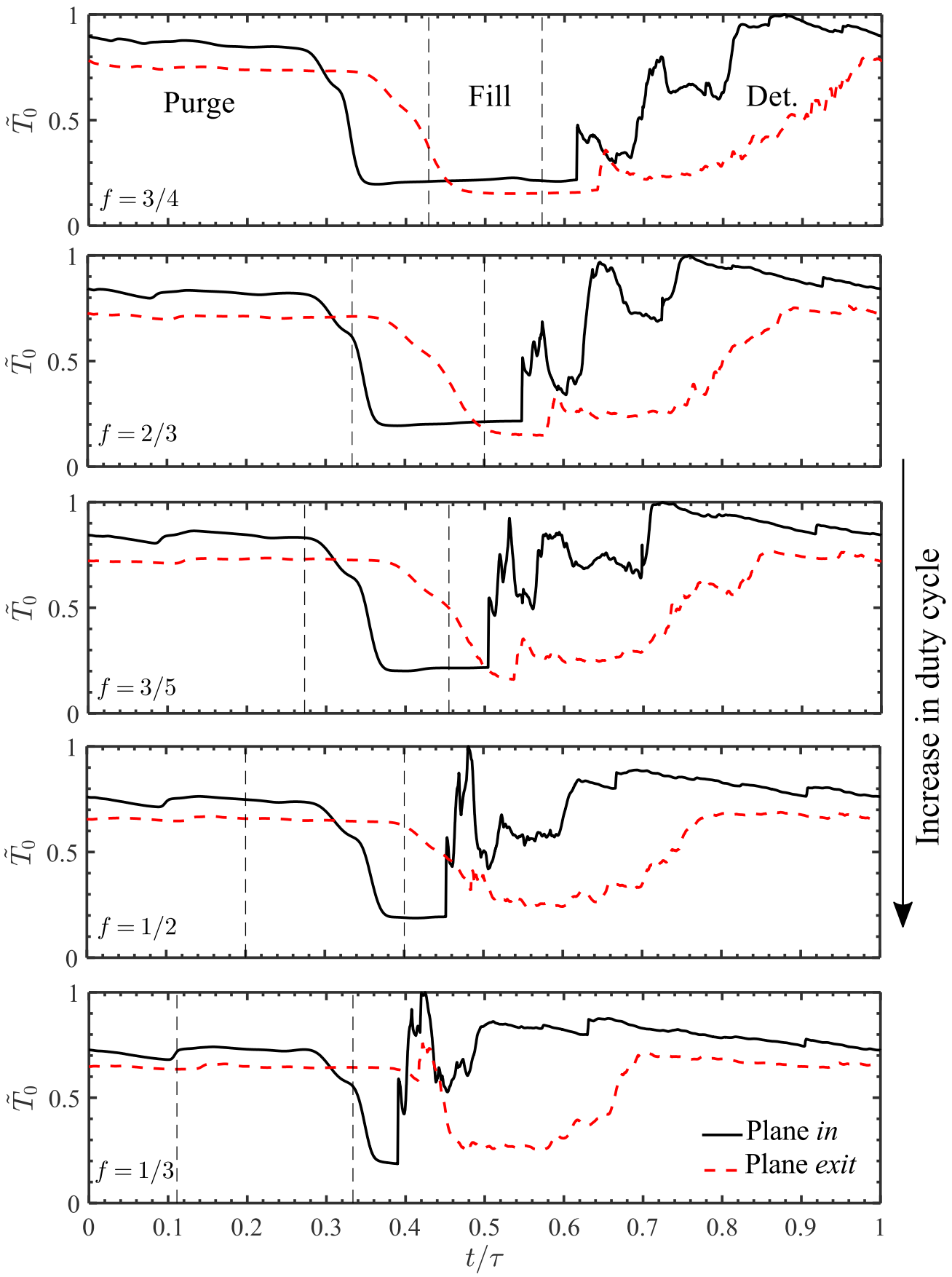

Figure 14: Variation of stage normalized temperature history with purge fraction for a constant rotor blade speed of $435 \mathrm{~m} / \mathrm{s}$. 
the efficiency when the amount of purge flow is reduced. It should indeed be possible to find an optimal rotor blade angle for a particular purge fraction.

The results also revealed that the stage efficiency increased when operating at higher input power settings (lower end of purge fraction). Such behaviour was linked to less severe fluctuations in temperature and rotor incidence angle. Increasing the power input to the turbine, by increasing the temperature and pressure of purge and fill flow should have a similar effect on turbine performance.

Following the conclusions above, the analysis of geometrical design is, therefore, a natural next step in the development of PDC-turbine systems. Previous studies show that the level of reaction can have a major impact on the efficiency of axial turbines under pulsating flow and that high reaction designs are less sensitive to off-design conditions. Still, this might not be the case under detonation flow, and a reaction level study could clarify this aspect. The present study only considered the effect of synchronized detonation flow. Sequential detonation might allow reducing some of the flow instabilities at the stator-rotor interface. However, one must also consider the effect of tube-to-tube interference that might affect the mixture detonability of adjacent tubes.

\section{Acknowledgements}

This work is financially supported by the E.U. under the "ULTIMATE - Ultra Low Emission Technology Innovations for Mid-century Aircraft Turbine Engines" Project co-funded by the European Commission within the Horizon 2020 Programme (2014-2020) under Grant Agreement no. 633436. The computations were performed on resources at Chalmers Centre for Computational Science and Engineering (C3SE) provided by the Swedish National Infrastructure for Computing (SNIC). The authors would like to acknowledge the US Department of Energy for the part-time faculty appointment of Prof. Paniagua to the Faculty Research Participation Program at the National Energy Technology Laboratory.

\section{Nomenclature}


${ }_{481}$ A Area $\left(\mathrm{m}^{2}\right)$

${ }_{482} D_{\mathrm{CJ}}$ Detonation wave velocity $(\mathrm{m} / \mathrm{s})$

${ }_{483} f \quad$ Purge fraction

${ }_{484} h_{0} \quad$ Total enthalpy $(\mathrm{J})$

${ }_{485} \quad p \quad$ Static pressure $(\mathrm{Pa})$

${ }_{486} \quad p_{0} \quad$ Stagnation pressure $(\mathrm{Pa})$

${ }_{487} p_{\mathrm{VN}} \quad$ von Neumann peak pressure $(\mathrm{Pa})$

${ }_{488} \quad t \quad$ Time $(\mathrm{s})$

${ }_{489} \quad T_{0} \quad$ Total temperature $(\mathrm{K})$

${ }_{490} t_{f} \quad$ Fill Time

${ }_{491} t_{p} \quad$ Purge time $(\mathrm{s})$

${ }_{492} U \quad$ Rotor blade speed $(\mathrm{m} / \mathrm{s})$

${ }_{493} u \quad$ Normal velocity $(\mathrm{m} / \mathrm{s})$

${ }_{494} w \quad$ Specific work $(\mathrm{J} / \mathrm{kg})$

495 Greek symbols

${ }_{496} \quad \alpha_{2} \quad$ Stator exit angle $\left(^{\circ}\right)$

${ }_{497} \quad \beta_{2} \quad$ Rotor incidence angle $\left(^{\circ}\right)$

${ }_{498} \Delta \quad$ Variation

${ }_{499} \quad \eta \quad$ Isentropic efficiency

${ }^{500} \gamma \quad$ Ratio of specific heats 
$\rho \quad$ Fluid density $\left(\mathrm{kg} / \mathrm{m}^{3}\right)$

\section{Subscripts}

1 Pre-detonation state

2 Post-detonation state

ma Cycle mass-averaged

wa Cycle work-averaged

\section{References}

[1] T. Grönstedt, C. Xisto, V. Sethi, A. Rolt, N. G. Rosa, A. Seitz, K. Yakinthos, S. Donnerhack, P. Newton, N. Tantot, O. Schmitz, A. Lundbladh, Ultra low emission technology innovations for mid-century aircraft turbine engines, in: Proceedings of the ASME Turbo Expo, 2016. doi:10.1115/GT2016-56123.

[2] T. Grönstedt, M. Irannezhad, X. Lei, O. Thulin, A. Lundbladh, First and second law analysis of future aircraft engines, Journal of Engineering for Gas Turbines and Power 136 (3) (2014) 031202-031202-10. doi:10.1115/1.4025727.

[3] C. Xisto, F. Ali, O. Petit, T. Grönstedt, A. Rolt, A. Lundbladh, Analytical model for the performance estimation of pre-cooled pulse detonation turbofan engines, in: Proceedings of the ASME Turbo Expo, 2017. doi:10.1115/GT2017-63776.

[4] C. Xisto, O. Petit, T. Grönstedt, A. Lundbladh, Assessment of $\mathrm{co}_{\mathbf{2}}$ and $\mathrm{no}_{\mathbf{x}}$ emissions in intercooled pulsed detonation turbofan engines, ASME J Eng Gas Turb Power, in pressdoi:10.1115/1.4040741.

[5] W. H. Heiser, D. T. Pratt, Thermodynamic cycle analysis of pulse detonation engines, Journal of Propulsion and Power 18 (1) (2002) 68-76. doi:10.2514/2.5899.

[6] C. Brück, C. Tiedemann, D. Peitsch, Experimental investigations on highly loaded compressor airfoils with active flow control under non-steady flow conditions in a 3d-annular low-speed cascade, in: Proceedings of the ASME Turbo Expo, 2016. doi:10.1115/GT2016-56891.

[7] G. Paniagua, M. C. Iorio, N. Vinha, J. Sousa, Design and analysis of pioneering high supersonic axial turbines, International Journal of Mechanical Sciences 89 (2014) 65-77. doi:10.1016/j.ijmecsci.2014.08.014.

[8] J. Sousa, G. Paniagua, Entropy minimization design approach of supersonic internal passages, Entropy 17 (8) (2015) 5593-5610. doi:10.3390/e17085593. 
[9] J. Sousa, G. Paniagua, J. Saavedra, Aerodynamic response of internal passages to pulsating inlet supersonic conditions, Computers \& Fluids 149 (2017) 31-40. doi:10.1016/j.compfluid.2017.03.005.

[10] J. Sousa, G. Paniagua, E. C. Morata, Thermodynamic analysis of a gas turbine engine with a rotating detonation combustor, Applied Energy 195 (2017) 247-256. doi:10.1016/j.apenergy.2017.03.045.

[11] Z. Liu, J. Braun, G. Paniagua, Performance of axial turbines exposed to large fluctuations, in: 53rd AIAA/SAE/ASEE Joint Propulsion Conference, 2017. doi:10.2514/6.2017-4817.

[12] F. Ornano, J. Braun, B. H. Saracoglu, G. Paniagua, Multi-stage nozzle-shape optimization for pulsed hydrogen-air detonation combustor, Advances in Mechanical Engineering 9 (2) (2017) 1-9. doi:10.1177/1687814017690955.

[13] A. St George, R. Driscoll, E. Gutmark, D. Munday, Experimental comparison of axial turbine performance under steady and pulsating flows, Journal of Turbomachinery 136 (11). doi:10.1115/1.4028115.

[14] K. P. Rouser, P. I. King, F. R. Schauer, R. Sondergaard, J. L. Hoke, L. P. Goss, Time-resolved flow properties in a turbine driven by pulsed detonations, Journal of Propulsion and Power 30 (6) (2014) 1528-1536. doi:10.2514/1.B34966.

[15] A. St. George, E. Gutmark, Trends in pulsating turbine performance: Pulse-detonation driven axial flow turbine, in: 50th AIAA Aerospace Sciences Meeting including the New Horizons Forum and Aerospace Exposition, 2012. doi:10.2514/6.2012-769.

[16] A. J. Dean, A. Rasheed, V. Tangirala, P. F. Pinard, Operation and noise transmission of an axial turbine driven by a pulse detonation combustors, in: Proceedings of the ASME Turbo Expo, 2005. doi:10.1115/GT2005-69141.

[17] A. Rasheed, A. H. Furman, A. J. Dean, Pressure measurements and attenuation in a hybrid multitube pulse detonation turbine system, Journal of Propulsion and Power 25 (1) (2009) 148-161. doi:10.2514/1.31893.

[18] A. Rasheed, A. H. Furman, A. J. Dean, Experimental investigations of the performance of a multitube pulse detonation turbine system, Journal of Propulsion and Power 27 (3) (2011) 586-596. doi:10.2514/1.B34013.

[19] F. H. Ma, J. Y. Choi, V. Yang, Thrust chamber dynamics and propulsive performance of multitube pulse detonation engines, Journal of Propulsion and Power 21 (4) (2005) 681-691. doi:10.2514/1.8182.

[20] A. Glaser, N. Caldwell, E. Gutmark, Performance of an axial flow turbine driven by multiple pulse detonation combustors, in: 45th AIAA Aerospace Sciences Meeting and Exhibit, 2007. doi:10.2514/6.20071244.

[21] S. George, Development and testing of pulsed and rotating detonation combustors, Ph.D. Thesis, University of Cincinnati (2016).

[22] D. VanZante, E. Envia, M. Turner, The attenuation of a detonation wave by an aircraft engine axial 
turbine stage, in: 18th ISABE Conference, 2007.

[23] A. Suresh, D. C. Hofer, V. E. Tangirala, Turbine efficiency for unsteady, periodic flows, Journal of Turbomachinery 134 (3) (2012) 034501-034501-6. doi:10.1115/1.4003246.

[24] E. Göttlich, F. Neumayer, J. Woisetschlager, W. Sanz, F. Heitmeir, Investigation of stator-rotor interaction in a transonic turbine stage using laser doppler velocimetry and pneumatic probes, Journal of Turbomachinery 126 (2) (2004) 297-305. doi:10.1115/1.1649745.

[25] E. Göttlich, J. Woisetschlager, P. Pieringer, B. Hampel, F. Heitmeir, Investigation of vortex shedding and wake-wake interaction in a transonic turbine stage using laser-doppler-velocimetry and particleimage-velocimetry, Journal of Turbomachinery 128 (1) (2006) 178-187. doi:10.1115/1.2103092.

[26] J. Páscoa, C. Xisto, E. Göttlich, Performance assessment limits in transonic 3d turbine stage blade rows using a mixing-plane approach, Journal of Mechanical Science and Technology 24 (10) (2010) 2035-2042. doi:10.1007/s12206-010-0713-9.

[27] M. A. Mawid, T. W. Park, B. Sekar, C. Arana, Application of pulse detonation combustion to turbofan engines, Journal of Engineering for Gas Turbines and Power 125 (1) (2003) 270-283. doi:10.1115/1.1494098.

[28] S. Yungster, K. Radhakrishnan, K. Breisacher, Computational study of nox formation in hydrogenfuelled pulse detonation engines, Combustion Theory and Modelling 10 (6) (2006) 981-1002. doi:10.1080/13647830600876629.

[29] R. Pecnik, P. Pieringer, W. Sanz, Numerical investigation of the secondary flow of a transonic turbine stage using various turbulence closures, in: Proceedings of the ASME Turbo Expo, 2005. doi:10.1115/GT2005-68754.

[30] G. D. Roy, S. M. Frolov, A. A. Borisov, D. W. Netzer, Pulse detonation propulsion: challenges, current status, and future perspective, Progress in Energy and Combustion Science 30 (6) (2004) 545-672. doi:10.1016/j.pecs.2004.05.001.

[31] G. L. Agafonov, S. M. Frolov, Computation of the detonation limits in gaseous hydrogen-containing mixtures, Combustion Explosion and Shock Waves 30 (1) (1994) 91-100. doi:10.1007/Bf00787891.

[32] M. Kaneshige, J. Shepherd, Detonation database, Report Technical Report FM97-8, Caltech, GALCIT (1997).

[33] S. Y. Yungster, K. Radhakrishnan, Pulsating one-dimensional detonations in hydrogen-air mixtures, Combustion Theory and Modelling 8 (4) (2004) 745-770. doi:10.1088/1364-7830/8/4/005.

[34] W. Benedick, C. Guirao, R. Knystautas, J. Lee, Critical Charge for the Direct Initiation of Detonation in Gaseous Fuel-Air Mixtures, Progress in Astronautics and Aeronautics, AIAA, 1986, pp. 181-202. doi:10.2514/5.9781600865800.0181.0202.

[35] ANSYS, ANSYS Fluent Theory Guide, ANSYS Inc., 2016. 
[36] N. A. Cumpsty, J. H. Horlock, Averaging nonuniform flow for a purpose, Journal of Turbomachinery 128 (1) (2006) 120-129. doi:10.1115/1.2098807.

[37] B. McBride, S. Gordon, Computer program for calculating and fitting thermodynamic functions, Report NASA RP-1271, NASA (1992).

[38] L. Landau, E. Lifshitz, One Dimensional Gas Flow, Vol. 6, Pergamon, 1987, pp. 361-413.

[39] M. Irannezhad, T. Grönstedt, L.-E. Eriksson, Limitation on tube filling in a pulse detonation engine, in: 20th ISABE Conference, 2011.

[40] M. Irannezhad, A numerical study of reacting flows using finite rate chemistry, Ph.D. Thesis, Chalmers University of Technology (2012). 
2018-09-05

\section{The efficiency of a pulsed detonation combustor-axial turbine integration}

Xisto, Carlos M.

Elsevier

Xisto C, Petit O, Gronstedt T, Rolt A, et al., (2018) The efficiency of a pulsed detonation combustor-axial turbine integration. Aerospace Science and Technology, Volumes 82-83, November 2018, pp. 80-91

https://doi.org/10.1016/j.ast.2018.08.038

Downloaded from Cranfield Library Services E-Repository 